\title{
A design tool for pressure microsensors based on FEM simulations
}

Conference Paper in Sensors and Actuators A Physical · September 1996

CITATIONS

21

6 authors, including:

G. Bistué

Universidad de Navarra

31 PUBLICATIONS 193 CITATIONS

SEE PROFILE

Santiago Garcia-Alonso

Universidad de Las Palmas de Gran Canaria

26 PUBLICATIONS 85 CITATIONS

SEE PROFILE
READS

65

Some of the authors of this publication are also working on these related projects:

Project MicroSCALE View project

Project Microfabrication technologies for biomedical applications View project 


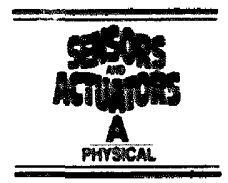

\title{
A design tool for pressure microsensors based on FEM simulations
}

\author{
G. Bistué u.*, J.G. Elizalde ", S. García-Alonso ', E. Castaño a, F.J. Gracia a , A. García-Alonso a \\ ${ }^{-}$Centro de Estudios e Investigaciones Técnicas de Guipuiccoa (CEIT). PO Bax 1555. E-20009 Sun Sebastiün. Spain \\ "Escuela Superior de Ingenieros Industriales, Universidad de Navarra. M. Lardizabal 15, E-20009 San Sebastian. Spain
}

\begin{abstract}
The main features involved in the design of a pressure sensor are the maximum non-destructive pressure and the sensitivity. In this work, these two characteristics are related to the following design variables: dimensions of the membrane and mechanical properties of the selected material. Von Misses stress and strain distributions have been calculated by the finite-element method (FEM). The knowledge of these distributions is a good design guideline for an accurate location of the piezoresistors. The results obtained have been applied to the design of silicon microsensors for bionedical and domestic applications. (O) 1997 Elsevier Science S.A.
\end{abstract}

Kẹwords: Silicon; Microsensors; Pressure; Simulation

\section{Introduction}

Monolithic silicon microstructures have been applied to a wide spectrum of mechanical microsensors. Using integrated circuit manufacturing technologies and silicon micromachining techniqus, comparatively low cost and small sensor sizes are achieved. Four strain gauges located in a thin membrane constiture the basis of pressure microsensors. Membrane dimensions are determined by sensor sensitivity and maximum non-destructive pressure (burst pressure). Both characteristics are related to the mechanical response of the membrane: stress and strain distributions. Mechanical behaviour of thin plates is a well-known engineering problem. An approximate method to calculate deflections and bending moments has been proposed [1]. However, no analyical expressions have been proposed to quantify burst pressure and membrane strains. Mechanical analysis of the membrane can be done by numerical methods too, such as the finiteelement method (FEM) [3,7], or the finite differences method [4]. Some studies about sensitivity have been reported $[2-4,6]$. These methods are not simple, and they are far from design concepts. Nevertheless, to the best of the authors' knowledge, no simple expressions have been reported to calculate sensor characteristics.

In this work, burst pressure and sensitivity are related to the main senso: design parameters: the membrane thickness and area, and the mechanical properties of the bulk material

\footnotetext{
${ }^{*}$ Corresponding author. Tel.: +3443212800 . Fax: +3443213076 E-mail: gbistue@ceit.es

(Young's modulus and Poisson ratio). A final expression is found as a design tool for pressure microsensors.

\section{Calculation method}

\subsection{Main characteristics of a pressure sensor}

\subsubsection{Sensitivity}

Sensitivity is commonly defined as

$s=\frac{V_{\mathrm{OUT}}}{V_{\mathrm{tN}} \Delta P}$

where $V_{\text {OUr }}$ and $V_{\mathrm{IN}}$ are the output and supply voltage and $\Delta P$ is the maximum applied pressure [5]. For a four-arm Wheatstone bridge, $V_{\mathrm{OUT}} / V_{\mathrm{IN}}$ is related to the fractional change in resistance as follows:

$\frac{V_{\mathrm{OUr}}}{V_{\mathrm{IN}}}=\frac{\Delta R}{R}$

The relationship between $\Delta R / R$ and longitudinal strain $(\epsilon)$ can be expressed by means of the gauge factor:

$\mathrm{GF}=\frac{\Delta R / R}{\epsilon}$

Combining Eqs. (1), (2) and (3) we can obtain the expression for sensitivity versus mechanical characteristics:

$s=\mathrm{GF} \frac{\epsilon}{\Delta P}$ 


\subsubsection{Burst pressure}

Burst pressure was calculated using the Von Misses stress distribution. This is a complex criterion, and it lithes alccount of normal and shear stresses.

\subsection{Strain and strexs distributien.s}

The strain and stress distributions of the membrane were calculated by FEM simulations, asing the COSMOS/M/ ENGINEER" sottware |8|. Isotropic material and plane stress hypotheses were assumed. As shown in previously reported works [1.9]. both are conservative hypotheses and a guarintee for a sitie design. The diaphragm of the sensor was modelled meshing with square shell elements. These elements have four nodes, hending and membrane capabilities and six degrees of freedom per node. Nodes at the edger of the mentbrane were considered built-in. Two planes of symmetiy were used to simplify the model.

\subsection{Dimensional anulwsis}

Data points given by FEM simulations form a numerical solution. These points were fitted using functions defined by dimensional analysis. This method allows the shape of at concrete relation to be previewed by means of the expected related variables.

\subsubsection{Maximum strain $\left(\epsilon_{31}\right)$}

The main variables that can alfect this parameter are supposed to be membrane arma $A\left[\mathrm{~m}^{-} \mid\right.$, membrane thickness I $|\mathrm{m}|$, applied pressure $P \mid \mathrm{N}$ m 2 . Young"s modulus $E \mid N$ $m^{-1}$ and Poisson's ratio ${ }^{\prime}$ | adimensionall. Strain values are proportional to the applied pressure. as is shown in the fundamental equations of the mechanical problem |II. As a consequence of Hooke's law. and lor keeping the dimensional homogencity $\epsilon_{11} \approx P / l$. On the other hand, the thicker the membrane is. the higger the deformations will be. so:

$\epsilon_{N}=K \frac{P A^{\prime}}{E t^{2}}$

The constants $K_{\mathrm{t}}$ and $N$ must be entimated from the $\mathrm{FEM}$ calculated data poinis. Obviously, the influence of Poisson?: ratio cannot be determined, ats it has no units.

\subsubsection{Burst pressure $(B P)$}

We can apply the same reasioning to the burst pressure. In this casce the main valriables are membrane area $d\left|\mathrm{~m}^{2}\right|$. membrane thickness / $|\mathrm{m}|$, facture lensile stress o $\sigma_{\mathrm{N}} \mid \mathrm{N}$ $m$ "I. and Poisson's ration "/ without dimension |. The expected dimensional function is

$\mathrm{BP}=K_{\mathrm{B} \mid} \frac{\sigma_{\mathrm{M} \mid} T^{N}}{A^{\mathrm{N}}}$

The constants $K_{131}$ and $N$ must he estimated from the FEM calcutiated data points.

\section{Results and discussion}

\subsection{Ftivl simulation results}

Fig. I shows the strain distribution of a membrame. Tensile and compressive stress anes can be identitied taking into

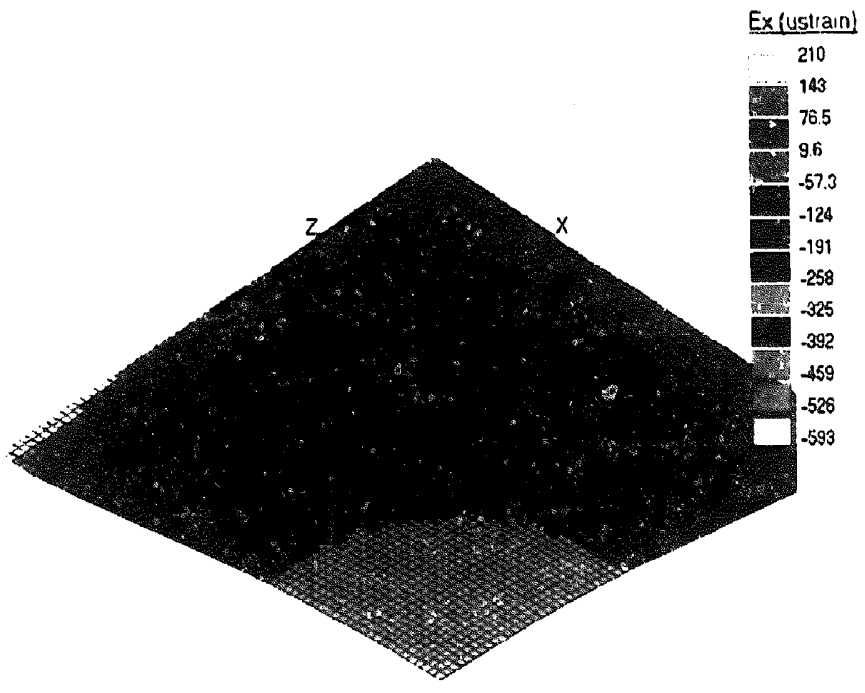

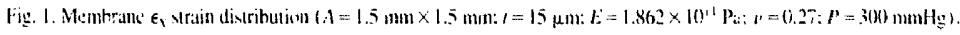




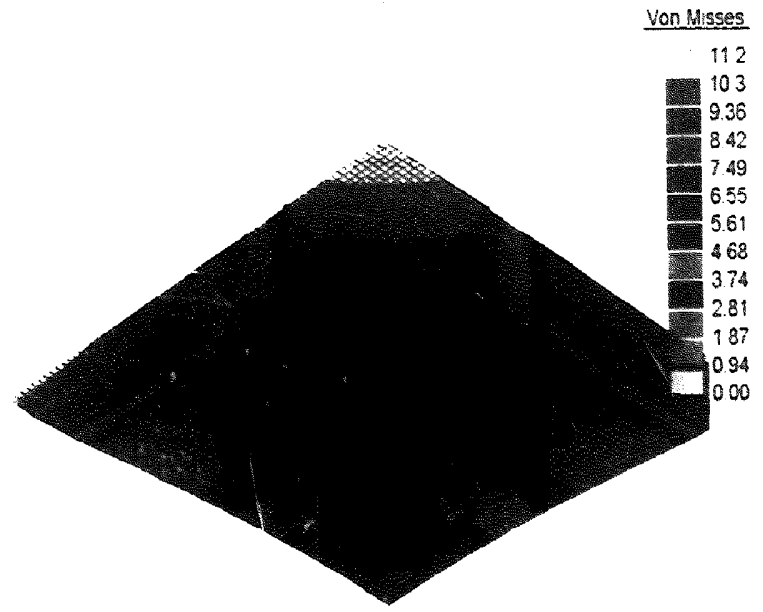

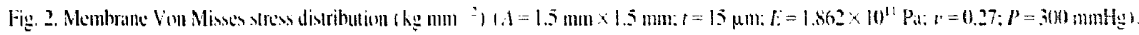

account on the sign of the deformation. Fig. Z shows the Von Misses stress distribution. The points of maximum stress are at the middle of the nembrane edges.

\subsection{Data points fit}

Figs. 3 and 4 show data points calculated from FEM simulations, and the fitted functions. The factor $N$ is approximately equal to one. According to Eys. (5) and $(6)$ general functions can be written as

$\mathrm{BP}=\frac{3 . t}{1-v^{2}} \frac{\sigma_{111 \mathrm{X}} r^{2}}{A}$

$\left.E_{\mathrm{M}}=0.1061 !-v^{2}\right) \frac{P A}{E I^{2}}$

$\left.s_{11}=0.106: 1-r^{-}\right) \mathrm{GF} \frac{A}{E t^{2}}$

\section{Application to the design of sensors for biomedical and domestic applications}

An invasive blood-pressure transducer must be able to work in the -100 to $+300 \mathrm{mmHg}$ pressure range. with a sensitivity of $20 \mu \mathrm{V} \mathrm{V} 1 \mathrm{mmHg}$. The membrame (1.5) $\mathrm{mm} \times 1.5 \mathrm{~mm}$ ) is obtained using anisotropic etching and the electrochemical etch-stop techniqus. Based on exposed results, a $15 \mu$ m thick nembrane is needed to achieve the desired sensitivity, supporting overpressures five times the aiximum pressure.

Silicon seasors oriented to washing machines necd maximam sensitivity, thereiore. the thickness of the diaphragm is determined by the burst pressure. $5 \mu \mathrm{m}$ thick membranes

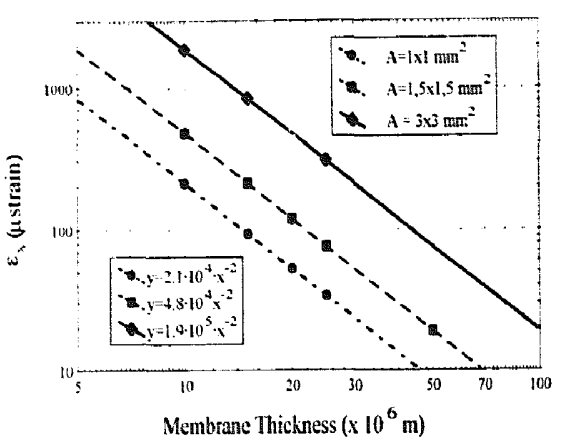

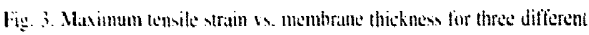

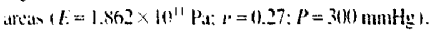

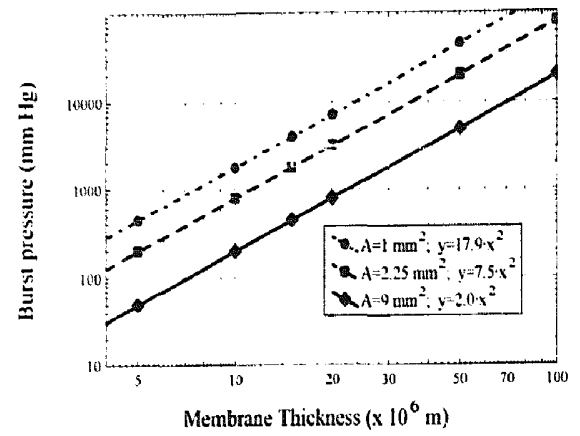

Fig. 4. Barst prensture us, membrane thichencss tor these different areas

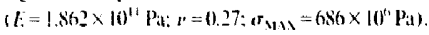

support overpressures of eight times the full-scale pressure $(350 \mathrm{mmH}, \mathrm{O})$, with a sensitivity of $8 \mu \mathrm{V} \mathrm{V}=1 \mathrm{mmH}_{2} \mathrm{O}^{-1}$. A common differential pressure of $2 \mathrm{mmH}_{2} \mathrm{O}$ causes a 0.0164 $\mathrm{mV} \mathrm{V}-1$ output, which can be detected by actual monitions. 


\section{Conclusions}

A set of simple equations relating burst pressure and maximum strain to the main design variables has been established. An expression that allows a value of the pressure sensitivity to be estimated hals been proposed. Tensile and compressive zones of the membrane have been determined by a strain distribution diagram. The points of maximum stress during pressure application have been identitied. Results have been applied to the design of a microsensor for hiomedical applications $(-100)$ to $+300 \mathrm{mmHg})$ and a microsens's for domestic appliances $\left(0\right.$ to $\left.+350 \mathrm{mmH}_{2}()\right)$.

\section{References}

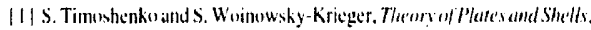
McGiraw-Hill. Now York. 1959. pp. 5-32.

$12 \mid$ H. Tanigawa T. Ishitara. iv1. Hirata and K. Suzuki. MOS integrated

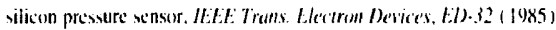
$1191-1195$.

|3| B. Folkmer, H.L. Ofleteins. H. Sandmater, W Lang, A. Seidl. P. (iroth and $R$. Pressmat. A simulation fool for mechanical selnot designt. Sonsors and A tuatory A. 32 (1942) , 521-524.

H A. Kovites and A. Stoflet. Mechanical analysis of polycrystalline and single-crystalline silicon microstructures, Sensors and Acheness $A$, fl$\$ 2(199+) 672-679$.

151 K. Hoffmann. An Introdaction a Measurements lsimg Strain Gages. Hollinger Baldwin Messlechnick GinbH. Alsbach. Germany. 1989. pp. $145 \% 153$.

|6| K. Suzuki, T. Jshihara, M. Hirata and H. Tanigatwa, Nonlintat antalysis of a CMOS integrated silicun pressure sensur. IEFE: Trams. Electrom

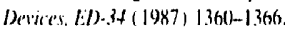

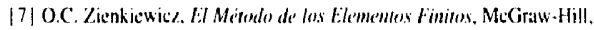
New York. 1982, pp. 6-15.

|8| P. Seide. Theoretical Mamal of Cosmos/M. S.R.A. Corp.. Sinta Monica, CA. 1992, pp. 141-147.

$|9|$ S. Marco. O. Ruiz. J. Samitier and J.R. Moranle. Simulacion mecánica de estructuras realizadas en silicio: aplicación al disenoo de sensores de

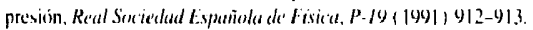

\section{Biographies}

Guillermo Bistur received his B.S. degree in electrical engineering from the University of Navarra, San Sebatián, in 1994. He is currently pursuing his Ph.D. degree in electrical engineering. Since 1994. he has been working as a research and development engineer at the Microelectronics Department of the Centro de Estudios e Investigaciones Técnicas (CEIT) in San Sebastian. His research interest is domestic appliance pressure-sensor development.

Jorge Garcia Elizalde received his B.S. degree in electrical engineering from the University of Navarra, San Sebastian, in 1992. He is currently pursuing his $\mathrm{Ph}$.D. degrec in electrical engineering. Since 1992, he has been working as a research and development eigineer at the Microelectronics Department of the Centro de Estudios a Investigaciones Técnicas (CEIT) in San Sebastian. His research interest is a hiomedical pressure-sensor development. For further contact, his email address is jgelizalde (a) ceit.es.

Samiago Garcta-Almso received his B.S. degree in mechanical engineering from the University of Navarra. San Sebastian. in 1990. Since 1990, he has heen working as at research and development engineer at the Materials Department of the Centro de Estudios a Investigaciones Técnicas (CEIT) and at the Engineering Schoor in San Sebustran. He is currently pursuing his Ph.D. degree in mechanical engineering. His research interest is the study of mechamicil oroperties of composite materials.

Enrique Castaño received his B.S. degree in physical science from the Complutense Universily of Madrid in 1987 and the Ph.D. degree in physical science from the University of Navarra, San Sebastián. in 1992. Since 1993 he has been working as a research and development scientist at the Centro de Estudios e Investigaciones Técnicas ( CEIT) in San Sebastian. His research interests are solid-stite microsensors. For further contact, his e-mail address is ecastano(a) ceit.es.

F. Jarier Gracia received his B.S. and Ph.D. degrees in physical science from the University of Navarra in 1973 and 1978. respectively. Since 1978 he has heen with the Department of Electronics, University of Navarra, where he now works as professor of electronics at the Escuela Superior Ingenieros Industriales (ESIl). Concurrently, he was with the Faculty of Physics as a professor of physical clectronics from 1978 to 1985. In 1983, he joined the Department of Electricity, Electronics and Automation of the Centro de Estudios e Investigaciones Técnicass de Guipúzcoa (CEIT). In 1990 he moved to the Microelectronics Department of CEIT. Currently, his research interests include the design and technical development of sensors and silicon microsystems. His e-mail address is jgracia (a)ceit.es.

Andrés Garrá-Alonso received his B.S. and Ph.D. degrees in electrical engineering from the University of Navarra. San Sebastian, in 1988 and 1993, respectively. Since 1988, he has been working as a research and development engineer at the Microelectronics Department of the Centro de Estudios a Investigaciones Técnicas (CEIT) in San Sebastiain. His research interests are solid-state microsensors. For turther contact, his e-mail address is angalonso(a)ceit.es. 